Developments in Recruitment and Selection Research

\author{
Eva Derous and Filip De Fruyt \\ Ghent University, Belgium
}

Author Note

Eva Derous, Department of Personnel Management, Work and Organizational Psychology, Ghent University. Filip De Fruyt, Department of Developmental, Personality and Social Psychology, Ghent University.

Correspondence regarding this article can be addressed to Eva Derous, Department of Personnel Management, Work and Organizational Psychology, Ghent University, Henri Dunantlaan 2, 9000 Ghent, Belgium. E-mail: eva.derous@ugent.be. 


\section{Developments in Recruitment and Selection Research}

Recruitment and selection $(\mathrm{R} \& S)$ constitute one of the oldest areas in the field of applied psychology and still is one of the most important domains of talent management and human resources (HR), appealing to a large number of researchers and HR practitioners (Ryan \& Ployhart, 2014). Times are changing and the area of $R \& S$ is also rapidly evolving, pushed forward by strategic issues, societal pressures, and technological developments.

Given the so-called "war" for talent that organizations suffer during the last decades in Europe and beyond, R\&S has even taken a more central place in the organization's strategy and their talent management in particular. The strategic role that $\mathrm{R} \& \mathrm{~S}$ plays in organizations has triggered a host of new developments, and has expanded traditional conceptualizations of $R \& S$ practices with insights from other disciplines, like economics and marketing (e.g., organizational branding; Yu \& Cable, 2012), information, communication and computer technology (e.g., social media, Van Iddekinge, Lanivich, Roth, \& Junco, 2013), and even biology (e.g., biomarkers; Becker, \& Mengers, 2013). Consider for instance "recruitment games" (Marsh, 2011) or serious games that are introduced as a hybrid kind of recruitment and testing tools. Such new tools increase efficiency by simultaneously attracting and screening applicants early in the hiring cycle, thereby creating more compressed hiring and socialization cycles for both individuals and organizations. At the same time, high technological recruitment games have a marketing intent as they might brand the organization's image, help with publication relations, and strategically position the organization in the local job market.

Aside from any strategic impetus, diverse societal challenges in Europe also push R\&S practices forward. One of the most challenging and pressing drivers are current demographic changes, due to the currently unseen migratory waves in Europe, which in due time may create an even more complex society and diverse labor market (e.g., Artuc, Docquier, Özden, \& Parsons, 2015). Indeed, given these dynamics, it is our expectation that issues like the assessment of minority 
groups (regarding age, gender, ethnicity, disabilities, ...) will become even more important in the forthcoming years and will continue challenging well-established staffing models/tools that fit Western-centered HR policies and thinking about talented workers.

Finally, one of the greatest changes in R\&S practices is considered to be "technology-linked" (Ryan et al., 2015). Indeed, technological advancements reshape R\&S practices by means of multimedia tools (like mobile testing, video résumés, use of LinkedIn as recruitment platform, etc.) and the use of online applicant tracking systems (as part of human resource information systems) that might increase the efficiency of the recruitment and assessment process to both recruiters and applicants. Although some multimedia applications like social networking websites (e.g., Kluemper, Davison, Cao, \& Wu, 2015; Roth, Bobko, Van Iddekinge, \& Thatcher, 2013), unproctored/mobile testing (e.g., Burke, Mahoney-Philips, Bowler, \& Downey, 2011), and video résumés (e.g., Hiemstra \& Derous, 2015) are increasingly used by applicants and practitioners, research is somewhat lagging behind as still not that much is known about the properties (like security of test materials) and efficacy (like test validity) of several technology-enhanced assessments compared to the more traditional recruitment and assessment tools.

However and despite the enduring calls for evidence-based approaches in business and management (e.g., Rynes, Giluk, \& Brown, 2007), there is a risk that researchers and practitioners drift apart instead of flock together to address new challenges. Much of the debate on the researchpractice divide, reminds us of the Indian parable of the blind men and the elephant: By examining different parts of the elephant, and by virtue of one's physical impairment, one would not be able to see the whole from its parts ("..And so these men of Indostan, Disputed loud and long, Each in his own opinion, Exceeding stiff and strong though each were partly in the right, And all were in the wrong." John Godfrey Saxe). Though, this is not to say that new developments do not come with several tensions, that seem inherent to the research-practice divide, like the desire for innovation (e.g., use of technology-enhanced assessments) and the desire for efficiency (e.g., losing highly 
qualified applicant that feel threatened by high-tech assessment tools). Without taking any stand on the current debate, we believe action is not only needed to advance our scientific knowledge, but also to discuss any inherent tensions to bridge the research-practice divide in this regard.

Taken together, the examples mentioned above show that $R \& S$ is a very dynamic area of constant concern to both researchers and applied psychologists in Europe and beyond. Contemporary challenges have motivated a group of European researchers to establish a network to advance our insights in developments in R\&S (Nikolaou, Anderson, \& Salgado, 2012). In 2011, the European Network of Selection Researchers (ENESER) was established by Neil Anderson, Ioannis Nikolaou, and Jesus Salgado, following the successful completion of the first supported Small Group Meeting (SGM) at the Athens University of Economics and Business, supported by the European Association of Work and Organizational Psychologists (EAWOP). One year later (June 2012), a second meeting was held in Sheffield, UK, under the auspices of the University of Coventry (Garcia-Izquierdo, Derous, \& Searle, 2013). August 2014, then, we organized a third Small Group Meeting (SGM) in Ghent (Belgium) to strengthen the prolongation of the successful collaboration of the ENESER network under the auspices of both the European Association of Work and Organizational Psychology (EAWOP) and the Department of Personnel Management, Work and Organizational Psychology at the Ghent University.

The focus of the Small Group Meeting in Ghent was on the way strategic, societal, and technological challenges -like the organization's strive for excellence and competitive advantages, while accommodating demographic and technological changes- "(re)shape” our R\&S practices and avenues for further research. Our aim was to bring together both more experienced and younger researchers of the R\&S field in an attempt to discuss their work in an open and collaborative atmosphere. In total, 23 papers were presented during this three-day meeting, organized around five thematic sessions (recruitment, interview, tools, applicant reactions, personality) that covered a wide range of topics and allowed for in-depth discussions. All authors were invited to submit their work 
for publication consideration in the International Journal of Selection and Assessment. Submitted papers (\#11 in total) were all peer-reviewed in the usual double-blind way by experienced R\&S researchers that were not connected to/ did not participate to the Small Group Meeting.

The current issue presents five papers that primarily adhere to some societal and strategic challenges, although much more good work was presented during the SGM (e.g., on technological challenges). Topics covered in this current issue specifically relate to the unintended (and maybe unexpected) effects of transparency on applicants' test performance (Jacksch \& Klehe, 2016), ethnic differences in applicants' perceptions of cognitive ability testing (Oostrom \& De Soete, 2016), the validation of an inductive reasoning test to identify applicants and employees' maladaptive traits like aggression (Galić, 2016), the relative importance of job seekers' personal values in organizational attractiveness (Vanderstukken, Van den Broeck, \& Proost, 2016), and the effectiveness/side effects of word-of-mouth as a recruitment tool (Van Hoye, Weijters, \& Lievens, 2016).

At the start of the Small Group Meeting, a practitioners' meeting was organized with the support of HR Square (a local professional HR journal), at the old Sint-Autbertus church of the medieval Monasterium cloister in the city center of Ghent. The rationale of the practitioners' meeting was to bring together Belgian practitioners with well-known European researchers adhering to the principles of evidence-based management- to discuss "hypes and hopes in R\&S" as well as any potential research-practice gaps and -more importantly- ways to overcome such gaps. During the "kick-off" event at the historical venue, main findings from an empirical study on the research-practice divide in $\mathrm{R} \& \mathrm{~S}$ as well as testimonies from practice were discussed of which some findings are presented in the last paper of this Special Issue (Ryan \& Derous, 2016).

While we could dwell on all strategic/societal/technological changes, the key message here is that the area of $\mathrm{R} \& \mathrm{~S}$ is rapidly evolving, affecting a broad range of topics in searching, attracting, and assessing talented workers, that warrants close monitoring and examination. The ENESER 
network aims to address, discuss, and study such developments among scholars and practitioners. More work has yet to be done and will be done, for instance, at the fourth ENESER meeting in Amsterdam (Spring 2016), which will also be held under the auspices of EAWOP.

In closing, we would like to thank Neil Anderson, Wilfried De Corte, Filip Lievens, Ioannis Nikolaou, Bart Wille, the Faculty of Psychology and Educational Sciences at Ghent University, and HR Square for their support. Last but not least, we thank Chockalingam Viswesvaran for making this IJSA Special Issue on the ENESER Small Group Meeting possible.

\section{References}

Artuç, E., Docquier, F., Özden, Ç., \& Parsons, C. (2015). A global assessment of human capital mobility: The role of non-OECD destinations. World Development, 65, 6-26. doi: 10.1016/j.worlddev.2014.04.004

Burke, E., Mahoney-Philips, J., Bowler, W., \& Downey, K. (2011). Going online with assessment: Putting the science of assessment to the test of client need and 21st century technologies. In N. Tippins \& Adler (Eds.). Technology-enhanced assessment of talent (Siop Professional Practice Series, pp. 355-379). Chichester: Wiley.

Galić, Z. (2016). Conditional Reasoning Test for Aggression: Further evidence about incremental validity. International Journal of Selection and Assessment, xx, xx-xx. doi: $\mathrm{xxx}$

Garcia-Izquierdo, A. L., Derous, E., \& Searle, R. (2013). Recruitment and Selection in Europe: One step beyond. Journal of Work and Organizational Psychology, 29, 1-2. doi: $10.5093 / \operatorname{tr} 2013 \mathrm{a} 1$

Hiemstra, A. M. F., \& Derous, E. (2015). Video résumés portrayed: Findings and challenges. In I. Nikolaou en J. K. Oostrom (Eds.), Employee Recruitment, Selection, and Assessment: Contemporary issues for theory and practice (pp. 45-60). New York, NY: Psychology Press/Taylor \& Francis. 
Jacksch, V., \& Klehe, U.-C. (2016). Unintended consequences of transparency during personnel selection: Benefitting some candidates, but harming others? International Journal of Selection and Assessment, xx, xx-xx. doi: xx.

Kluemper, D. H., Davison, H. K., Cao, X., \& Wu, B. (2015). Social networking websites and personnel selection: A call for academic research. In I. Nikolaou en J. K. Oostrom (Eds.), Employee Recruitment, Selection, and Assessment: Contemporary issues for theory and practice (pp. 61-79. New York, NY: Psychology Press/Taylor \& Francis.

Marsh, T. (2011). Serious games continuum: Between games for purpose and experiential environments for purpose. Entertainment Computing, 2, 61-68. doi:10.1016/j.entcom.2010.12.004

Nikolaou, I., Anderson, N., \& Salgado, J. (2012). Advances in Selection and Assessment in Europe. International Journal of Selection and Assessment, 20, 383-384. doi: 10.1111/ijsa. 12000

Oostrom, J. K., \& De Soete, B. (2016). Ethnic differences in perceptions of cognitive ability tests: The explanatory role of self-serving attributions. International Journal of Selection and Assessment, xx, xx-xx. doi: $\mathrm{xxx}$

Roth, Ph. L., Bobko, Ph., Van Iddekinge, C. H., \& Thatcher, J. B. (2013). Social media in employee-selection decisions: A research agenda for uncharted territory. Journal of Management. Advanced online publication. doi: 10.1177/0149206313503018

Ryan, A. M., \& Derous, E. (2016). Highlighting tensions in recruitment and selection research and Practice. International Journal of Selection and Assessment, xx, xx-xx. doi: xxx.

Ryan, A. M., Inceoglu, I., Bartram, D., Golubovich, Y., Grand, J., Reeder, M., Derous, E., Nikolaou, I., \& Yao, X. (2015). Trends in testing: Highlights of a global survey. In I. Nikolaou en J. K. Oostrom (Eds.), Employee Recruitment, Selection, and Assessment: 
Contemporary issues for theory and practice (pp. 136-153). New York, NY: Psychology Press/Taylor \& Francis.

Ryan, A. M., \& Ployhart, R. E. (2014). A century of selection. Annual Review of Psychology, 65, 20.1-20.25. doi: 10.1146/annurev-psych-010213-115134

Rynes, S. L., Giluk, T. L., \& Brown, K. G. (2007). The very separate worlds of academic and practitioners periodicals in human resource management: Implications for evidence - based management. Academy of Management Journal, 50, 987-1008. doi:

10.5465/AMJ.2007.27151939

Vanderstukken, A., Van den Broeck, A., \& Proost, K. (2016). For love or for money: Intrinsic And extrinsic value congruence in recruitment. International Journal of Selection and Assessment, $x x, \mathrm{xx}-\mathrm{xx}$. doi: $\mathrm{xxx}$

Van Hoye, G., Weijters, B., \& Lievens, F. (2016). Social influences in recruitment: When is word-of-mouth most effective? International Journal of Selection and Assessment, $x x, \mathrm{xx}-\mathrm{xx}$. doi: $\mathrm{xxx}$

Van Iddekinge, C. H., Lanivich, S. E., Roth, Ph. L., \& Junco, E. (2013). Social Media for Selection? Validity and Adverse Impact Potential of a Facebook-Based Assessment. Journal of Management. Advance online publication. doi:10.1177/0149206313515524

Yu, K. Y. T., \& Cable, D. M. (2012). Recruitment and competitive advantage : A brand equity perspective. In S. W. J. Kozlowski (Ed.), The Oxford Handbook of IndustrialOrganizational Psychology (pp. 197-220). New York: Oxford University Press. 